\title{
Integrated knowledge translation to advance noncommunicable disease policy and practice in South Africa: application of the Exploration, Preparation, Implementation, and Sustainment (EPIS) framework
}

\author{
Nasreen S. Jessani ${ }^{1,2^{*}} \mathbb{C}$, Anke Rohwer ${ }^{1}$, Bey-Marrie Schmidt ${ }^{3,4}$ and Peter Delobelle 5,6
}

\begin{abstract}
Background: In response to the "know-do" gap, several initiatives have been implemented to enhance evidenceinformed decision-making (EIDM). These include individual training, organizational culture change management, and legislative changes. The importance of relationships and stakeholder engagement in EIDM has led to an evolution of models and approaches including integrated knowledge translation (IKT). IKT has emerged as a key strategy for ensuring that engagement is equitable, demand-driven, and responsive. As a result, the African-German Collaboration for Evidence-Based Healthcare and Public Health in Africa (CEBHA+) incorporated an IKT approach to influence noncommunicable diseases (NCD) policy and practice. We documented the phased process of developing, implementing, and monitoring the IKT approach in South Africa; and explored the appropriateness of using the exploration, preparation, implementation, and sustainment (EPIS) framework for this purpose.
\end{abstract}

Methods: We mapped the South Africa IKT approach onto the EPIS framework using a framework analysis approach. Notes of team meetings, stakeholder matrices, and engagement strategies were analysed and purposefully plotted against the four phases of the framework in order to populate the different constructs. We discussed and finalized the analysis in a series of online iterations until consensus was reached.

Results: The mapping exercise revealed an IKT approach that was much more iterative, dynamic, and engaging than initially thought. Several constructs (phase-agnostic) remained important and stable across EPIS phases: stable and supportive funding; committed and competent leadership; skilled and dedicated IKT champions; diverse and established personal networks; a conducive and enabling policy environment; and boundary-spanning intermediaries. Constructs such as "innovations" constantly evolved and adapted to the changing inner and outer contexts (phase-specific).

Conclusions: Using the EPIS framework to interrogate, reflect on, and document our IKT experiences proved extremely relevant and useful. Phase-agnostic constructs proved critical to ensure resilience and agility of NCD

\footnotetext{
*Correspondence: njessani@sun.ac.za

${ }^{1}$ Division of Epidemiology and Biostatistics, Centre for Evidence-Based

Health Care, Faculty of Medicine and Health Sciences, Stellenbosch

University, Cape Town, South Africa

Full list of author information is available at the end of the article
}

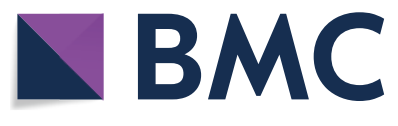

(c) The Author(s) 2021. Open Access This article is licensed under a Creative Commons Attribution 4.0 International License, which permits use, sharing, adaptation, distribution and reproduction in any medium or format, as long as you give appropriate credit to the original author(s) and the source, provide a link to the Creative Commons licence, and indicate if changes were made. The images or other third party material in this article are included in the article's Creative Commons licence, unless indicated otherwise in a credit line to the material. If material is not included in the article's Creative Commons licence and your intended use is not permitted by statutory regulation or exceeds the permitted use, you will need to obtain permission directly from the copyright holder. To view a copy of this licence, visit http://creativecommons.org/licenses/by/4.0/. The Creative Commons Public Domain Dedication waiver (http://creativeco mmons.org/publicdomain/zero/1.0/) applies to the data made available in this article, unless otherwise stated in a credit line to the data. 
deliberations and policies in the face of highly dynamic and changing local contexts, particularly in view of the current coronavirus disease 2019 (COVID-19) pandemic. Bridging IKT with a framework from implementation science helps to reflect on this process and can guide the development and planning of similar interventions and strategies.

Keywords: South Africa, Low- and middle-income countries, Integrated knowledge translation, Research uptake, Embedded research, Implementation research, Noncommunicable diseases, Stakeholder engagement, Exploration, preparation, implementation, and sustainment framework, Evidence-informed decision-making

\section{Background}

Effective translation of research evidence into policy and practice is important for improving health outcomes and reducing health inequities $[1,2]$. There are several complexities, however, associated with how and to what extent research evidence is translated into policy and practice [2]. These complexities (also referred to as the "know-do" gap) can be explained by factors related to researchers, decision-makers, their engagement, and the context in which they operate [3-7]. For example, researchers may misunderstand the needs of decisionmakers and present the "right answers to the wrong questions" [8]. Decision-makers may not use existing research evidence in their decision-making, or they may use research evidence in a manner that was not intended by the research community, or they may adapt research evidence to fit certain political needs and agendas [8]. Similarly, decision-makers are often unable to articulate their research needs as answerable research questions $[2,9,10]$. Continuous and effective engagement between researchers and decision-makers requires time and resources. It is often reliant on long-standing and/or personal relationships, which has advantages, such as longterm trust and confidence in the partnership, but also risks when key actors for example change position and are no longer able to facilitate the engagement $[11,12]$. Complex social and political factors (played out in the relationship between researchers and decision-makers) also enhance or hinder effective use or uptake of research evidence into policy and practice [13].

In response to the "know-do" gap, several initiatives have been promoted, including individual training, organizational culture change management, and legislative changes such as resolutions to better use research evidence for decision-making [14]. This has given rise to several models and frameworks for enhancing evidence-informed decision-making (EIDM) [15-21]. The increased focus on the importance of relationships [11, 12, 22-26] and stakeholder engagement [8, 27-31] led to further evolution of these frameworks to what is now referred to as integrated knowledge translation (IKT): "an approach or set of processes that can lead to the generation of knowledge for optimizing healthcare delivery systems and improving health system performance and associated outcomes" [32]. Implementation science, on the other hand, is defined as the "scientific study of methods to promote the systematic uptake of research findings and other evidence-based practices into routine practice, and, hence, to improve the quality and effectiveness of health services and care" [33]. Applying an implementation science lens to systematically reflect on and draw out experiences of IKT approaches or processes provides an opportunity to address the "know-do" gap [34]. Additionally, there is a need for research on the implementation, monitoring and evaluation of interventions or approaches for translating research evidence in health policy and practice decision-making, specifically in African settings [35, 36].

The Collaboration for Evidence-Based Healthcare and Public Health in Africa (CEBHA+) (https://www. cebha-plus.org/) is an African-German research consortium funded by the Federal Ministry of Education and Research (BMBF) in Germany. It focuses on three noncommunicable diseases (NCDs) (road traffic injuries, diabetes, and hypertension), and includes an IKT approach to ensure the uptake and use of research. Research objectives for each partner country were formulated as part of a priority-setting exercise carried out with health decision-makers and researchers in sub-Saharan Africa [37]. The five African country partners (Ethiopia, Malawi, Rwanda, Uganda, and South Africa) developed countryspecific IKT approaches, which are currently implemented and monitored alongside the different research activities. In South Africa, the CEBHA+ country partners include the Centre for Evidence-Based Health Care (CEBHC) at Stellenbosch University, the Chronic Disease Initiative for Africa (CDIA) at the University of Cape Town, and Cochrane South Africa (CSA) at the South African Medical Research Council (SAMRC).

The CEBHA+ coordinated IKT approach was envisioned as a six-step process [38] (Fig. 1) that commenced with a foundational workshop for all CEBHA+ partners. This workshop was designed and implemented by CEBHC [39] in October 2018. Draft stakeholder analyses and IKT strategies for key identified CEBHA + stakeholders were developed by each CEBHA+ African country at the workshop (Step 1). These were further refined with input from objective 


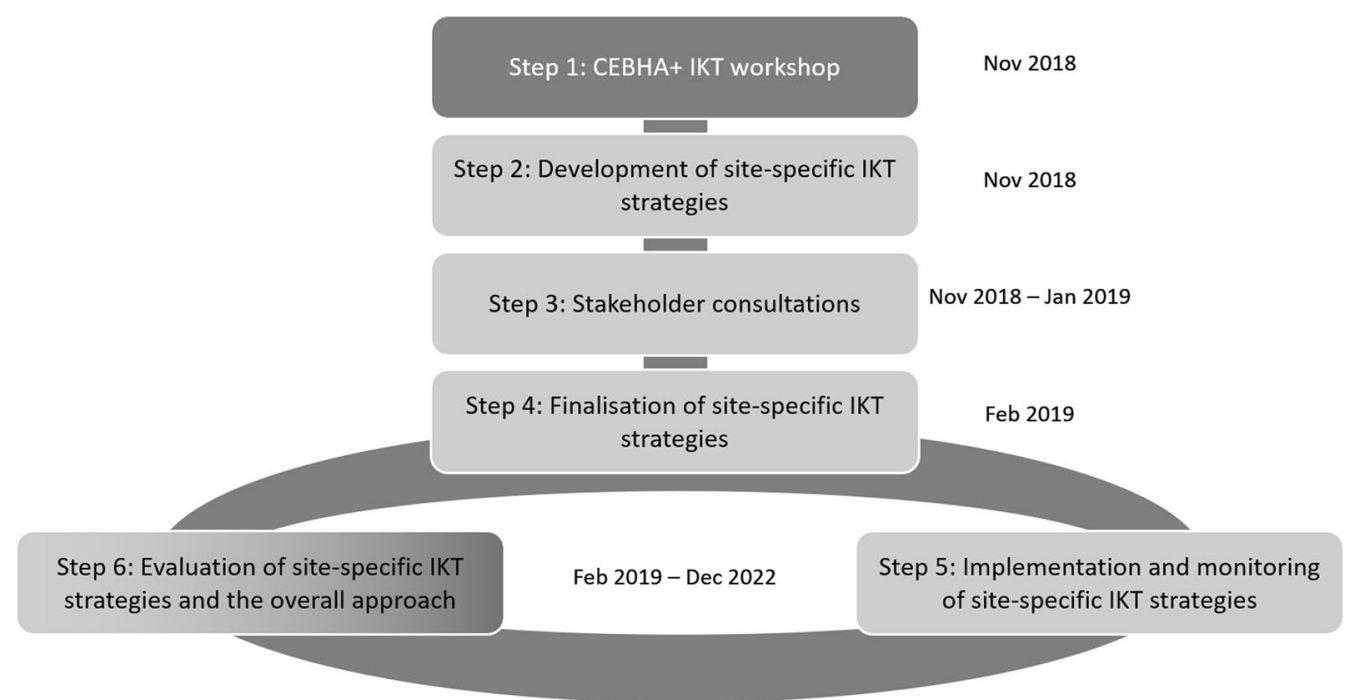

Fig. 1 Planned IKT approach [38]

colleagues (Step 2) several of the identified stakeholders (Step 3), and then finalized (Step 4). While the strategies varied by stakeholder and country, in South Africa some of the activities included regular scheduled meetings between CEBHA+ and stakeholders; being available for ad hoc consultations on NCD-related matters; tailoring outputs to their preferences; organizing a national NCD symposium; disseminating research products such as publications, presentations, and issue briefs; and providing regular programme updates. Implementation commenced in February 2019, with monitoring embedded throughout the process (Step 5) and an overall evaluation of IKT activities and processes across the consortium (Step 6). The entire process, however, was iterative in nature and supported by a working group with IKT methods expertise, training opportunities. Step 6-a semi-external cross-country evaluation of the CEBHA+ IKT approach-will be implemented by one of the German partners, the Ludwig Maximilian University of Munich (LMU), which is not directly involved in operationalizing country-specific IKT approaches [38].

The objective of this paper is to complement the multi-site semi-external evaluation with a deep-dive description of the South African six-step IKT approach, using an implementation science lens guided by the exploration, preparation, implementation, and sustainment (EPIS) framework [40]. This will lead to two outcomes: one, a documentation of the phased process of developing, implementing and monitoring the IKT approach, in order to contribute to growing research in the field from African settings; and two, exploration of the appropriateness and relevance of the EPIS framework for this purpose, thereby providing new insights into the intersection between IKT and implementation science.

\section{Methods}

We used a systematic approach to reflect on and map the planning and implementation of our IKT approach based on a cycle of internal discussions, including exploring the relevance of existing implementation frameworks. The discussion was initiated by a group deliberation in workshop format to screen the constructs of the Consolidated Framework for Intervention Research (CFIR) developed by Damschroder et al. [41] for its applicability to mapping the IKT approach in South Africa. CFIR is a well-known and popular framework that presents a taxonomy for conceptualizing and distinguishing between a wide range of contextual determinants of implementation success, including characteristics of the intervention, the implementing organization (inner setting), the outer setting, characteristics of individuals, and details of the implementation process. Given that deductive reasoning can be used to identify barriers and enablers that influence implementation outcomes, CFIR is considered a "determinants" framework in the classification of models, theories, and frameworks of implementation science proposed by Nilsen [42].

Despite its comprehensiveness and flexibility, however, the CFIR was found to be less suitable to capture the dynamics at play between the inner and outer settings of IKT implementation in our context [43], which involved boundary spanners and the importance of reciprocity 
in stakeholder relationships. It was decided to revisit the literature and conduct a more extensive mapping of available implementation frameworks and constructs, informed by the review by Tabak et al. [44] and complemented by models included in the Dissemination-Implementation Webtool (https://dissemination-implementa tion.org/content/diMain.aspx) based on a consensus to identify a model that would capture the stages of operationalization from conception to sustainability; interconnections between people, institutions, and constructs; and knowledge translation models used in health services policy. Several models were assessed based on their field of origin (public/health services sector), construct flexibility, implementation focus, and application at different levels of the socio-ecological framework [40, 45-48] and the EPIS framework selected for this paper. Table 1 below provides a summary of the models that were assessed, as well as their relative applicability to this study.

The EPIS framework, developed by Aarons et al. [40], describes four distinct phases to guide and describe the implementation process; enumerates factors within and across the inner and outer context across these phases; and outlines the factors that bridge the outer and inner context, as well as the interconnections and interlinkages that characterize the dynamics, complexity, and interplay of inner and outer contexts (Fig. 2). The EPIS framework was developed based on a literature review of implementation in public sector social and allied health service systems in the United States and found to be applicable to other countries and settings. However, until recently, the framework has shown limited prescriptive guidance for its use [56], and this paper aims to add evidence to the body of literature by focusing on its use in an uppermiddle-income country.

The six different steps of the CEBHA+ IKT approach in South Africa were first mapped onto the different phases of the EPIS Framework (the sustainment phase was excluded given that the programme is still underway). The framework was then retrospectively applied to the process of IKT planning, implementation, and monitoring within CEBHA+ using a matrix analysis approach as described by Morse and Field [57]. Matrices allow mapping of relationships between as well as among constructs of interest. They also assist with exploring the relationship between constructs and theoretical concepts.

Several electronic data sources that were part of the South African planning and implementation folders were used to populate the EPIS matrix of constructs and phases. From the period since Step 1 (November 2018) until this reflection paper-Steps 5 and 6 (December 2020)-these sources include the South African CEBHA+ stakeholder analysis (November 2018), notes and minutes from eight quarterly South Africa CEBHA+ IKT team meetings, minutes from four consortium-wide meetings on IKT across all five countries, two presentations (2019 and 2020), and three scientific meeting presentations and posters (2020). We also consulted the individually tailored stakeholder engagement (or IKT) strategies for six stakeholders deemed to be priorities for the South African CEBHA+ team. Constructs were added or edited where appropriate or necessary, and analysis was continued through a series of online iterations until consensus on the mapping was reached by all authors.

\section{Results}

The mapping exercise revealed an IKT approach that was much more iterative, dynamic, and engaging than initially thought. The original plan (Fig. 1) evolved with several of the six steps overlapping across phases and interacting bidirectionally and with each other, as shown in Fig. 3.

Several factors remained important and stable across phases (phase-agnostic), whereas others constantly evolved and adapted to the changing inner and outer contexts (phase-specific). Within each set of factors we discuss the EPIS subconstructs that are relevant to guide the interpretation of results. Other reflections and subconstructs not in the narrative can be found in Fig. 4 as well as Table 2, in which the constructs are embedded and colour-coded by phase. Factors that cut across phases remain in white, whilst those that are particular to a phase are shaded to match the colour of the relevant EPIS phase.

\section{Phase-agnostic factors \\ Outer context}

The idea to design and implement a comprehensive IKT approach as part of the CEBHA+ project was developed by CEBHA+ members during the exploration phase [37]. Although this was not a funding requirement or priority at that stage [58], our approach was very well received by the BMBF and led to an increased interest in and emphasis on IKT across the three phases reported on in this paper. Interest also grew amongst other BMBF-funded health networks during the preparation and implementation phases, allowing us to reflect on the interorganizational environment and network sub-constructs. For instance, during the implementation phase, interest in learning and adapting the approach developed by $\mathrm{CEBHA}+$ resulted in an invited presentation and training workshop by CEBHA+ colleagues at the BMBF cross-network meeting in Ghana in January 2020.

Another pervasive factor across the three phases was the policy environment in South Africa that not only considered NCDs a national priority but also promoted 


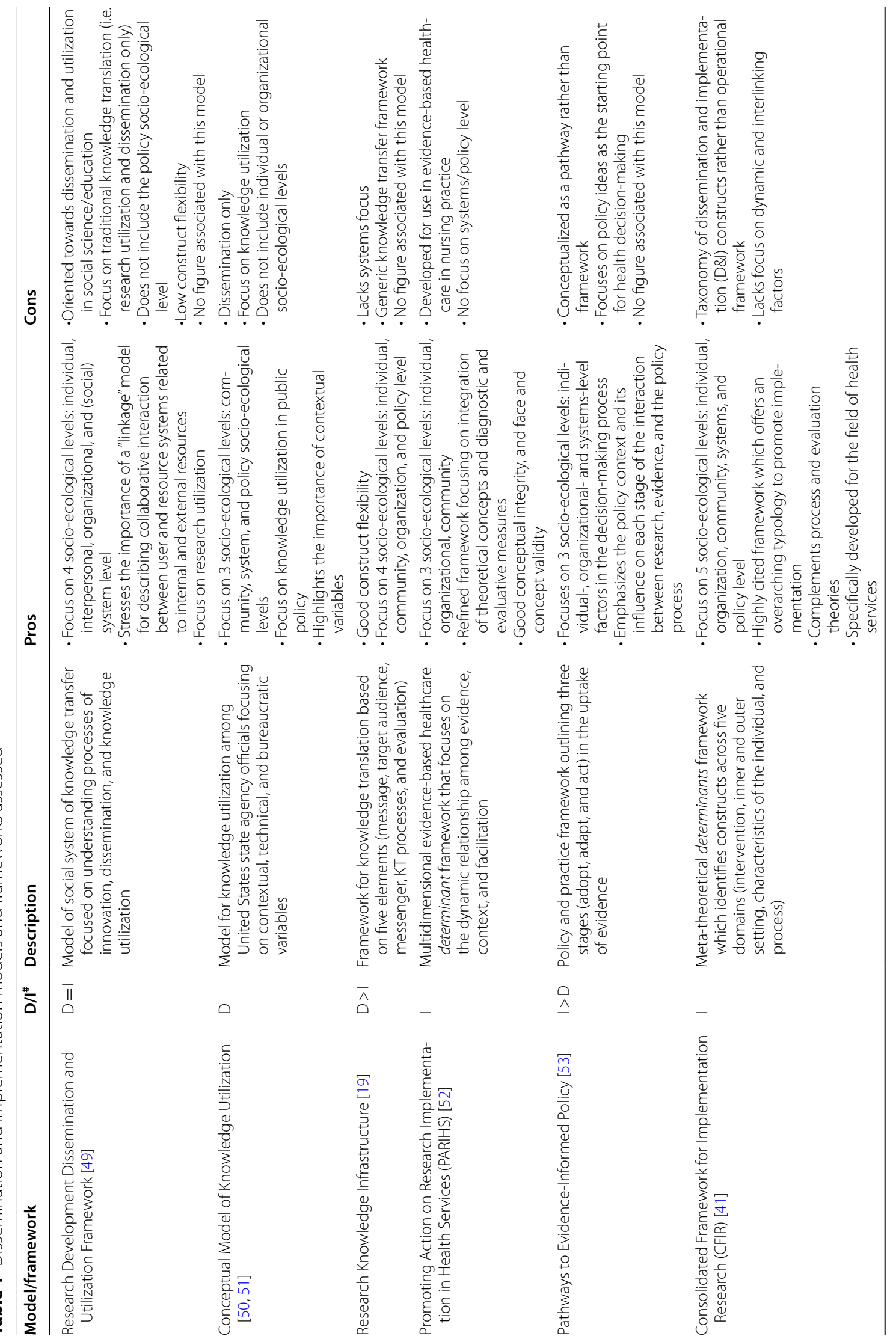




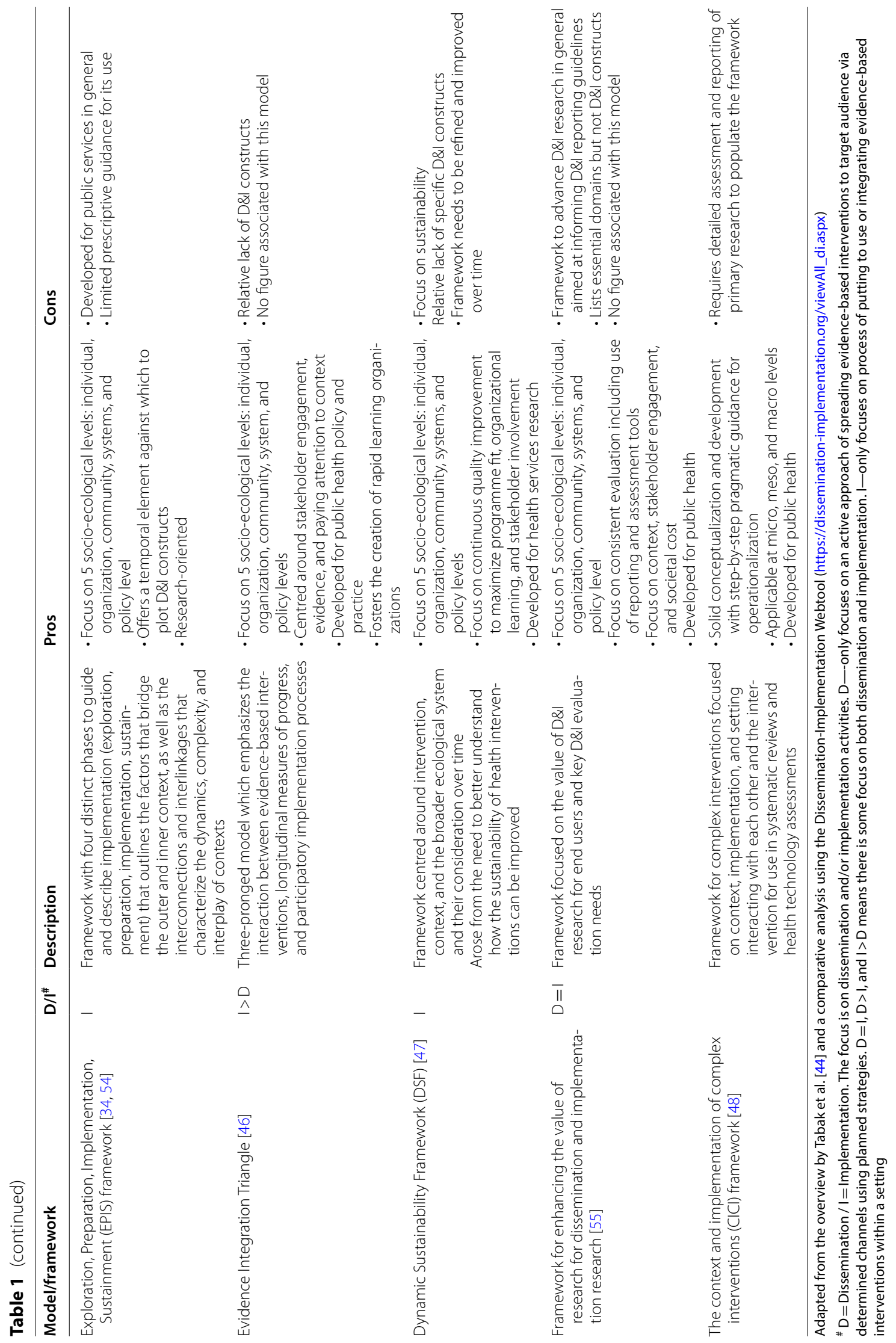




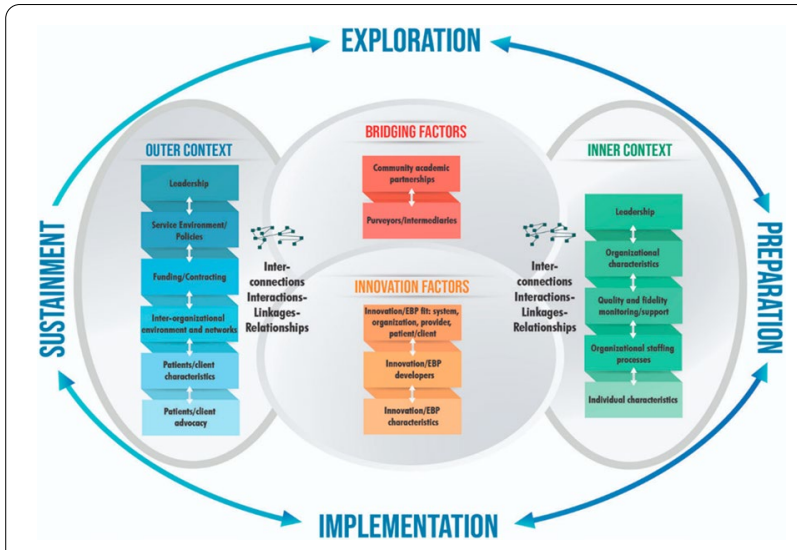

Fig. 2 EPIS framework [40]

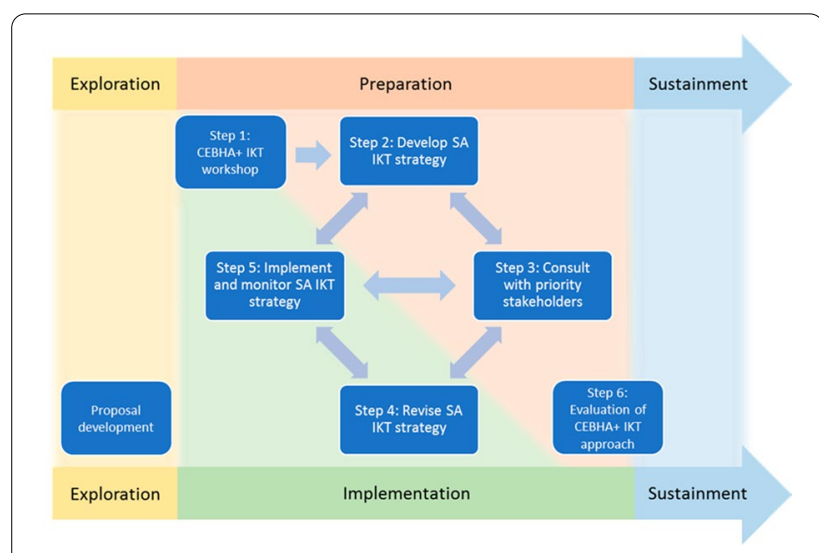

Fig. 3 Revised South Africa CEBHA+IKT approach

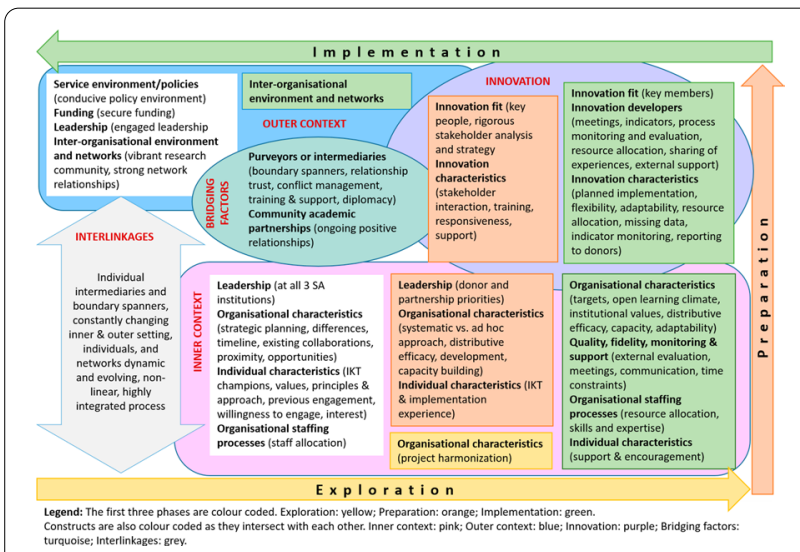

Fig. 4 CEBHA+ IKT mapped onto EPIS
EIDM. This enabled government officials to show interest in, and engage with, the CEBHA + team and the vibrant South African research community in the field of NCDs.

\section{Inner context}

Highly committed, competent, and supportive leadership was found to be integral to the IKT approach across the three phases, particularly given its novelty to the programme and "learning by doing" design. Furthermore, at the individual level, some members of the CEBHC team that had worked across sectors and organizations with specific experience and knowledge of IKT served as IKT trainers for the whole CEBHA+ project. In addition, some government colleagues had a background in research and were therefore able to navigate the academic requirements associated with the CEBHA+ research projects.

This was enhanced by several organizational characteristics, including organizational structure and culture. For example, having all three institutions in Cape Town within proximity to each other permitted efficient communication, engagement, and co-leadership on several aspects of the CEBHA+ project but also IKT endeavours. Convening stakeholder meetings, embarking on joint approaches, and sharing of administrative, financial, and human resources was therefore easier. The fact that IKT was already implemented by the different partners as a pillar of their institutional vision also contributed to and facilitated stakeholder buy-in, championship, design, and integration of an IKT approach into the CEBHA+ project.

\section{Bridging factors and interlinkages}

Unique to the project was a recognition that several colleagues from the three partners as well as many stakeholders acted as intermediaries, or boundary spanners, who traversed easily between environments and roles, in turn providing a better appreciation and understanding of the complexities of the respective institutional structures and cultures. These boundary spanners facilitated the breaking of silos, enhancing mutual understanding between settings, building of trust, and creating a more empathetic relationship. Colleagues serving as intermediaries who are skilled in diplomacy and conflict management also helped to overcome challenges with roles, communication, and finance issues. The German coordinator, the funders, and technical support partners of $\mathrm{CEBHA}+$ also played key bridging roles more internationally and across other health research networks.

Long-standing community-academic partnerships between individual team members at the three institutions with policy-makers at the provincial and national level facilitated access to many stakeholders. 
Table 2 EPIS phases and constructs

\begin{tabular}{|c|c|c|c|c|c|}
\hline & EPIS constructs and & Phase AGNOSTIC factors & & Phase SPECIFIC & actors \\
\hline & definitions $\mathbf{1}^{1,2}$ & & $\begin{array}{l}\text { Exploration } \\
\text { phase }\end{array}$ & Preparation phase & Implementation phase \\
\hline & $\begin{array}{l}\text { Leadership } \\
\text { "Characteristics and behaviours } \\
\text { of individuals involved in } \\
\text { oversight and/or decision- } \\
\text { making related to EBP } \\
\text { implementation within an } \\
\text { organisation." }\end{array}$ & $\begin{array}{l}\text { - Highly committed, involved } \\
\text { and supportive leadership } \\
\text { at all } 3 \text { South African } \\
\text { CEBHA+ partner } \\
\text { institutions }\end{array}$ & - & $\begin{array}{l}\text { Emphasis of the funder (BMBF) on } \\
\text { IKT increased relative priority of } \\
\text { an IKT-approach } \\
\text { Competing priorities within } \\
\text { CEBHA+ (e.g. to get research } \\
\text { projects started versus to plan for } \\
\text { IKT implementation) } \\
\text { Extent to which IKT would be } \\
\text { rewarded, supported and } \\
\text { expected, depended on each } \\
\text { institution's priorities }\end{array}$ & - \\
\hline 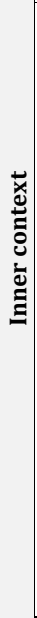 & $\begin{array}{l}\text { Organisational } \\
\text { characteristics } \\
\text { "Structures or processes that } \\
\text { take place and/or exist in } \\
\text { organisations that may } \\
\text { influence the process of } \\
\text { implementation." }\end{array}$ & $\begin{array}{l}\text { CEBHA+ SA comprises } 3 \\
\text { organisations, with varying foci } \\
\text { and strengths } \\
\text { - } \text { All } 3 \text { organisations are } \\
\text { geographically based in } \\
\text { Cape Town } \\
\text { - Strategic plans of all } 3 \\
\text { partners include IKT as a } \\
\text { key objective that cuts } \\
\text { across projects } \\
\text { They each convened on this } \\
\text { project since its inception } \\
\text { in } 2014 \text { and were therefore } \\
\text { involved in early } \\
\text { developments of the IKT } \\
\text { approach } \\
\text { This engagement was } \\
\text { preceded by several prior } \\
\text { collaborations between the } \\
3 \text { partners permitting } \\
\text { historic trust and relations } \\
\text { to serve as the bedrock for } \\
\text { this initiative } \\
\text { The opportunity for field } \\
\text { building was also attractive }\end{array}$ & $\begin{array}{l}\text { South } \\
\text { African IKT } \\
\text { approach } \\
\text { aligned with } \\
\text { and } \\
\text { paralleled } \\
\text { the broader } \\
\text { CEBHA+ } \\
\text { approach }\end{array}$ & $\begin{array}{l}\text { A systematic (vs ad-hoc) approach } \\
\text { to IKT was new and challenging } \\
\text { A formal, pre-specified 6-step plan } \\
\text { was developed to assist with a } \\
\text { more deliberative and reflective } \\
\text { process } \\
\text { A foundational workshop on IKT } \\
\text { and stakeholder engagement } \\
\text { enhanced skills and alignment } \\
\text { across partners } \\
\text { Strong and diverse capacity across } \\
\text { all } 3 \text { partners assisted with } \\
\text { distributive efficacy }\end{array}$ & $\begin{array}{l}\text { - There is a perceived pressure by the } \\
\text { South African partners to lead and } \\
\text { successfully implement the IKT approach } \\
\text { with other CEBHA+ peer organisations } \\
\text { looking to them for guidance } \\
\text { - Each partner organisation nominated 1-2 } \\
\text { team members to keep the IKT strategy } \\
\text { updated } \\
\text { - Circumstances required dual systems of } \\
\text { IKT: systematic as well as ad-hoc in order } \\
\text { to respond to the context } \\
\text { - Good learning climate } \\
\text { - Team feels valued, allowed to try new } \\
\text { methods } \\
\text { Strong and diverse capacity across all } 3 \\
\text { partners assisted with distributive } \\
\text { efficacy } \\
\text { Implementation adapted based on the SA } \\
\text { context }\end{array}$ \\
\hline & $\begin{array}{l}\text { Individual characteristics } \\
\text { "Shared or unique } \\
\text { characteristics of individuals } \\
\text { (e.g. provider, supervisor, } \\
\text { director) that influence the } \\
\text { process of implementation." }\end{array}$ & $\begin{array}{l}\text { - There are IKT champions in } \\
\text { each of the } 3 \text { partner } \\
\text { organizations } \\
\text { All individuals in the SA } \\
\text { partner sites share the IKT } \\
\text { values, principles, and }\end{array}$ & - & $\begin{array}{l}\text { Several individuals across the } 3 \\
\text { partners had interest and } \\
\text { experience in IKT and } \\
\text { implementation science }\end{array}$ & $\begin{array}{l}\text { Leadership is supportive and } \\
\text { encouraging of the SA IKT strategy } \\
\text { Variation in understanding of IKT across } \\
\text { CEBHA+ teams in each of the } 3 \text { partner } \\
\text { institutions: Some passive supporters; } \\
\text { some accepting; some confused. }\end{array}$ \\
\hline
\end{tabular}

Furthermore, the fact that many colleagues from the National Department of Health (NDoH) had these positive ongoing relationships with members of the three institutions prior to the launch of the CEBHA+ project led to mutual trust, willingness to attend meetings, collaborate, and demand evidence from CEBHA+ partners to contribute to South African NCD policies and practices. As CEBHA+ research was rolled out and results and their implications shared, different stakeholders were involved at various times. For instance, the CEBHC recently convened stakeholders from the government $(\mathrm{NDoH})$, research institutions (SAMRC), and civil society (The Cancer Association of South Africa) to discuss preliminary findings of a situation analysis of population-level interventions for diabetes and hypertension in South Africa. Similarly, multi-stakeholder engagement with management, health practitioners, and patients at two primary care clinics in Cape Town advanced individual counselling and enhanced group education for common NCDs, in turn leading to capacity strengthening of key partners.

\section{Phase-specific factors}

\section{Outer context}

With respect to the interorganizational environment, we highlight that having all three institutions based in Cape Town was a notable strength with respect to a pre-existing relationship with the Western Cape DoH. However, this geographical concentration also proved to be a significant weakness, especially during the preparation phase, given the limited or absent relationships with other provincial DoHs. The implementation phase brought with it expanded networks including emerging relationships with other provincial DoHs, facilitated mainly through an NCD symposium co-hosted by the CEBHA+ partners in South Africa and the NDoH. This is particularly important given the decentralization of health services in South Africa, which lends executive decision-making power to different tiers of government.

In the implementation phase, each country, including South Africa, had to adapt the IKT approach to an evolving outer context. For instance, shifting priorities in the policy environment during the COVID-19 pandemic required swift pivots within the IKT process. 
Table 2 (continued)

\begin{tabular}{|c|c|c|c|c|c|}
\hline & & $\begin{array}{ll}\text { approach } \\
\text { All } 3 \text { partners of CEBHA+ } \\
\text { SA have previously engaged } \\
\text { with stakeholders } \\
\text { - Scientific bodies: Varied } \\
\text { interest in engaging }\end{array}$ & & & \\
\hline & $\begin{array}{l}\text { Organisational staffing } \\
\text { processes } \\
\text { "The processes or procedures in } \\
\text { place at an organisation related } \\
\text { to the hiring, review, and } \\
\text { retention of staff involved in the } \\
\text { active delivery of the } \\
\text { innovation/EBP and its } \\
\text { implementation." }\end{array}$ & $\begin{array}{l}\text { Each partner institution } \\
\text { allocated at least one } \\
\text { skilled and experienced IKT } \\
\text { colleague to spearhead } \\
\text { CEBHA+ IKT work } \\
\text { There were dedicated } \\
\text { human and financial } \\
\text { resources }\end{array}$ & $\bullet$ & $\bullet$ & $\begin{array}{l}\text { - Skilled and experienced IKT colleagues } \\
\text { provided training and mentorship }\end{array}$ \\
\hline & $\begin{array}{l}\text { Quality, fidelity, monitoring } \\
\text { and support } \\
\text { "Processes or procedures } \\
\text { undertaken to ensure adherence } \\
\text { to active delivery of the } \\
\text { innovation/EBP and/or } \\
\text { implementation strategy." }\end{array}$ & - & - & - & $\begin{array}{ll}\text { - } & \begin{array}{l}\text { Support from German project partner } \\
\text { (LMU) }\end{array} \\
\text { - } & \text { External evaluation by funder } \\
\text { - } & \text { Evaluation of CEBHA+ IKT approach by } \\
\text { LMU } \\
\text { - }\end{array}$ \\
\hline$\ddot{x}$ & $\begin{array}{l}\text { Service environment/ } \\
\text { policies } \\
\text { "State and federal socio- } \\
\text { political and economic contexts } \\
\text { that influence the process of } \\
\text { implementation and } \\
\text { delivery/use of the innovation." }\end{array}$ & $\begin{array}{ll}\text { - } & \text { Policy environment } \\
\text { amenable to EIDM } \\
\text { - } & \text { Encouraging NCD public } \\
\text { policies } \\
\text { - Addressing NCDs is a } \\
\text { national priority }\end{array}$ & 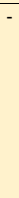 & - & - Changing priorities due to COVID-19 \\
\hline 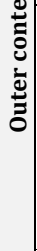 & $\begin{array}{l}\text { Funding } \\
\text { "Fiscal support provided by the } \\
\text { system in which implementation } \\
\text { occurs. Fiscal support can } \\
\text { target multiple levels (e.g., staff } \\
\text { training, fidelity monitoring, } \\
\text { provision of the } \\
\text { innovation/EBP) involved in } \\
\text { implementation and } \\
\text { delivery/use of the innovation." }\end{array}$ & - Funding from BMBF & - & - & - \\
\hline & $\begin{array}{l}\text { Leadership } \\
\text { "Characteristics and behaviors }\end{array}$ & $\begin{array}{ll}\text { - Interested and engaged } \\
\text { government officials }\end{array}$ & 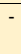 & - & - \\
\hline
\end{tabular}

\section{Inner context}

While all three South African CEBHA+ partners had previously engaged with stakeholders, support by the funder in the preparation phase increased the relative priority of IKT and provided an opportunity for a more structured and explicit IKT design in the preparation and implementation phases. This led to a deliberate CEBHA+ South African IKT approach developed in line with the broader CEBHA+ programme across all African CEBHA+ partner countries during the preparation phase. During the early stage of implementation, organizational characteristics such as readiness for change and absorptive capacity were found to be important. Although IKT was a priority within CEBHA+, the extent to which activities (that fell) within the remit of IKT would be rewarded, supported, and expected was relative to institutional priorities as well as readiness for change. Although the time for monitoring and implementing IKT in parallel with other CEBHA+ research activities proved challenging, the learning climate was very encouraging with the team feeling not only valued but also free to try new strategies and methods. In addition, the structured reflection allowed dedicated commitment from IKT team members as an organizational staffing strategy.

Finally, individual adopter characteristics were important, as instituting a systematic approach to IKT was new and proved challenging for many colleagues. Although individual attitudes were favourable, in the larger team there were some champions, some passive supporters, and some confusion. Due to varying experience in IKT and implementation science, some team members perceived a pressure to lead and successfully implement IKT in South Africa because peers were looking for guidance. For quality, fidelity, monitoring, and support purposes, virtual meetings were organized bimonthly during the implementation phase to monitor progress and adjust where necessary. This was complemented by informal communication, whether face to face or via email, as and when needed.

\section{Innovation}

As per Nilsen [42], innovation is the "implementation object", which in this case was an embedded IKT approach. The ability of the IKT approach to be adaptable to a complex system that involved many stakeholders and 
Table 2 (continued)

\begin{tabular}{|c|c|c|c|c|c|}
\hline & $\begin{array}{l}\text { of key decision-makers } \\
\text { pertinent at all levels who are } \\
\text { necessary but not sufficient to } \\
\text { facilitate or promote the } \\
\text { implementation process and } \\
\text { delivery/use of the innovation." }\end{array}$ & & & & \\
\hline & $\begin{array}{l}\text { Inter-organisational } \\
\text { environment and networks } \\
\text { "Relationships of professional } \\
\text { organizations through which } \\
\text { knowledge of the } \\
\text { innovation/EBP is shared } \\
\text { and/or goals related to the } \\
\text { innovation/EBP } \\
\text { implementation are } \\
\text { developed/established." }\end{array}$ & $\begin{array}{l}\text { - Vibrant research } \\
\text { community focusing on } \\
\text { NCDs } \\
\text { - Strong network between } \\
\text { CEBHA+ organisations } \\
\text { - Strong relationships with } \\
\text { NDoH, WCDoH, SA MRC, } \\
\text { GIZ }\end{array}$ & - & - & $\begin{array}{l}\text { Emerging network between other BMBF- } \\
\text { funded research consortia } \\
\text { Emerging relationships between other } \\
\text { provincial DoH's }\end{array}$ \\
\hline & $\begin{array}{l}\text { Innovation fit } \\
\text { "The extent to which the } \\
\text { innovation/EBP fits the needs of } \\
\text { the population } \\
\text { served or context in which it is } \\
\text { implemented." }\end{array}$ & - & - & $\begin{array}{l}\text { - Key individuals from the SA } \\
\text { CEBHA+ partners drove the } \\
\text { implementation and monitoring } \\
\text { - Rigorous stakeholder analysis } \\
\text { conducted } \\
\text { - Detailed IKT strategy for priority } \\
\text { stakeholders created }\end{array}$ & $\begin{array}{l}\text { Key members of NDoH facilitated } \\
\text { engagement }\end{array}$ \\
\hline 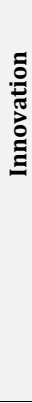 & $\begin{array}{l}\text { Innovation characteristics } \\
\text { "Features or qualities of } \\
\text { innovations to be implemented." }\end{array}$ & - & - & $\begin{array}{l}\text { Met frequently with stakeholders: } \\
\text { on engagement strategy, desired } \\
\text { disseminations products and } \\
\text { mediums } \\
\text { - Stakeholder engagement informed } \\
\text { the (adaptable) IKT strategy } \\
\text { - Implemented training where } \\
\text { necessary } \\
\text { - Responded to urgent requests for } \\
\text { evidence } \\
\text { - Support from LMU for formative } \\
\text { and summative evaluation }\end{array}$ & $\begin{array}{l}\text { - Implementation mostly according to plan } \\
\text { Plan adapted according to opportunity, } \\
\text { changing political context and input from } \\
\text { stakeholders } \\
\text { - Research projects within CEBHA+ arising } \\
\text { at different time points, resulting in new } \\
\text { stakeholders } \\
\text { - NCD Research Symposium convened } \\
\text { - } \quad \text { Need time to engage and monitor } \\
\text { - all SA partners } \\
\text { Implementation indicators not always } \\
\text { adequate to capture essence of } \\
\text { engagement } \\
\text { Reporting to donors at selected time } \\
\text { points }\end{array}$ \\
\hline
\end{tabular}

evolving relationships was a key element of innovation characteristics. While the IKT approach and strategy was implemented mostly according to plan, it was adapted according to opportunity, changing political context, and input from stakeholders. This resulted in convening an NCD research symposium as a key activity in 2020 but also strengthened the need to monitor implementation indicators despite missing data being a challenge at times.

Innovation fit therefore was an important consideration. In the preparation phase, this included conducting a thorough stakeholder analysis, a stakeholder prioritization exercise, and design of a detailed IKT strategy for each priority stakeholder. Frequent meetings with key stakeholders permitted a better understanding of their engagement preferences, evidence needs, training requests, and output/product choices. A tailored engagement strategy and response was implemented based on this information, and adapted according to opportunities, changing political context, and input from stakeholders. At the implementation phase, this was supported by the $\mathrm{NDoH}$.

Outcomes were captured systematically through a monitoring strategy maintained by IKT focal points across the three CEBHA+ partner institutions. Planned as well as opportunistic or demand-led engagements were captured in the IKT strategy documents in which the team reflected on process and progress, which was reported on as per donor requirements. This is particularly important for three reasons: (1) to adapt and evolve the IKT strategy as deemed necessary; (2) to share IKT experiences with other African CEBHA+ countries; and (3) to collect data relevant for external evaluation of the programme.

\section{Bridging factors and interlinkages}

Strong stakeholder relationships paid dividends during the implementation phase when key members of the $\mathrm{NDoH}$ facilitated engagement with other government stakeholders. For instance, when the South Africa CEBHA+ team hosted an NCD symposium in March 2020 , we were able to rely on our social capital in the government to secure the attendance and contribution of the Minister of Health. Similarly, when decision-makers wanted to understand more about COVID-19 and its intersection with NCDs, South Africa CEBHA+ colleagues were considered key academics to be consulted for rapid evidence reviews $[59,60]$.

\section{Discussion}

Since knowledge translation in global health started to gain traction in the lead-up towards the Millennium Development Goals [61, 62], efforts to bridge the implementation gap between knowledge production and EIDM in health policy have increased substantially. 
Table 2 (continued)

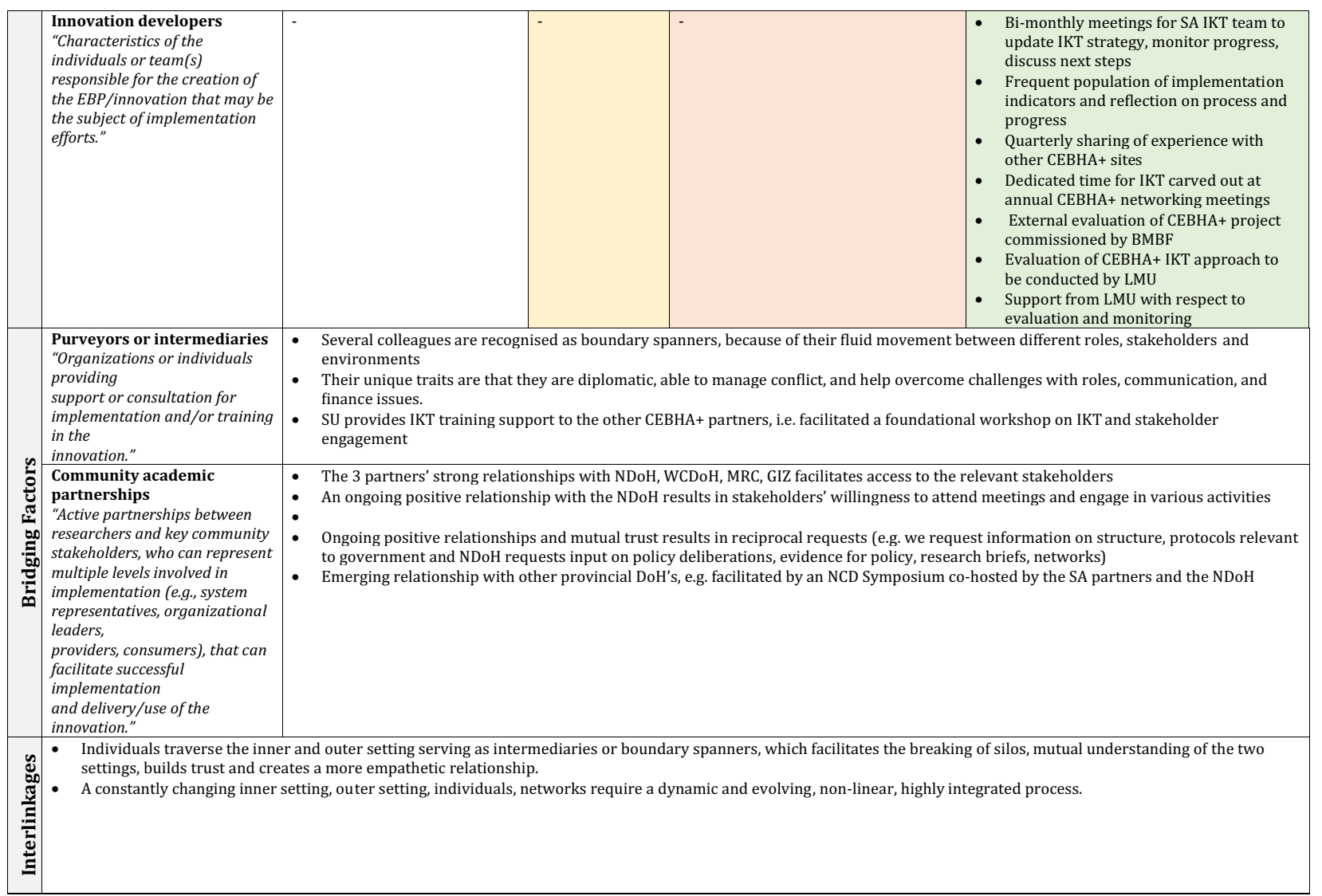

Sources: Aarons et al. [40]; Becan et al. [34]

CEBHA+: Collaboration for Evidence-based Healthcare and Public Health in Africa; SA: South Africa; IKT: Integrated knowledge translation; NdoH: National Department of Health; WCDoH: Western Cape Department of Health; MRC: Medical Research Council; GIZ: Deutsche Gesellschaft für Internationale Zusammenarbeit; LMU: Ludwig-Maximilian University of Munich; BMBF: Bundesministerium für Bildung und Forschung/Federal Ministry of Education and Research; EIDM: Evidenceinformed decision-making; NCD: Non-communicable disease; COVID-19: Coronavirus Disease

In low- and middle-income countries (LMICs), the marked inability of health systems to effectively implement evidence-informed interventions resulted in a call for implementation research in the design and execution of evidence-informed policy [63]. Although the relative paucity of peer-reviewed literature on IKT remains, there is an upward trend in documenting these experiences [64] as well as developing appropriate protocols [65]. Examples in Africa include the development of a KT platform in Zambia [66] and Malawi [67], and reflecting on KT strategies in Tunisia and Ivory Coast [35].

In this study, we documented our experience of developing, implementing, and monitoring the IKT approach in South Africa using the EPIS framework. As Becan et al. [34] pointed out, the EPIS model allows for examination of change processes at multiple levels, across time, and through successive stages toward implementation. The model was therefore well suited to understand and analyse our IKT approach. We combined the temporal aspect to demonstrate the dynamic and iterative IKT strategy that proved sensitive to changes in both the outer and inner context and was dependent on relationships and linkages between these. Using the EPIS framework to interrogate and document our IKT experiences proved extremely useful, particularly when mapping out the various phases as well as dynamic interactions that underpinned our IKT approach.

As outlined by Aarons et al. in their seminal paper [40], few implementation models explicitly recognize that different variables play crucially different roles at different time points during the process of implementation. In our study, several constructs remained stable across the three EPIS phases of exploration, preparation, and implementation, including stable and supportive funding, committed and competent leadership, skilled and dedicated IKT champions, diverse and established personal networks, a conducive and enabling policy environment, and boundary-spanning intermediaries. These phase-agnostic 
factors proved critical to ensure resilience and agility in the face of highly dynamic and changing local contexts and relationships, particularly as the COVID-19 pandemic hit. Some determinants of success were, however, phase-specific, which makes intuitive sense with respect to innovations. The IKT approach benefited from adaptation as the inner and outer context evolved. As a result, the team was able to respond to unanticipated demanddriven requests from decision-makers as well as pivot swiftly in response to crises. This agility will be important in the sustainment phase which we reflect later in the paper.

Reflections on the interlinkages and bridging constructs support the literature on the boundary spanners or knowledge brokers. Network analyses have often been used to unpack the role and power of such actors as both intermediaries as well as gatekeepers [26, 68-72]. While our experience with most stakeholders were positive in nature, several subconstructs within the inner context and outer context may shift this balance with a need for revised stakeholder analyses and relationship management $[11,73]$.

These findings will likely have implications for the sustainment phase where it will be important to capitalize on the phase-agnostic factors while managing for the phase-specific ones. Based on our experience and data, an institutionalization of IKT principles and practices such as authentic and mutually beneficial collaborations, a culture of EIDM, and capacity and resources for engagement and network maintenance will be critical. We propose that this can be imagined prospectively in our case as follows: (a) documenting the implementation of the IKT approach, specifically stakeholder engagement activities, will help us understand the changing needs and gaps in IKT or EIDM skills, and competencies amongst stakeholders; (b) maintaining collaborations as well as engaging with new stakeholders, particularly due to current and anticipated turnover within the government [11], potential internal organizational restructuring and/or staffing, and new actors in the external environment; (c) ensuring resilient institutional connections between CEBHA+ and stakeholders by going beyond single connections so as to have depth and breadth as well as diversity [26, 68]; (d) anticipating and planning for changing policy or decision-making processes; (e) continuously monitoring the implemented IKT approach to identify conversion or interchange between phase-agnostic and phase-specific factors across time, and whether newer strategies or innovations are required-this adaptation will be key to sustainment [56]; and (f) budgeting for cost-intense activities related to IKT. Longitudinal research of the CEBHA+ IKT strategy, as well as future initiatives such as the one described in this paper, would need to track some indicators to better understand sustainability and scalability which need more attention [56]. Such studies would help to understand the applicability of an IKT approach for projects and programmes beyond CEBHA+ that embed implementation science and IKT research into their design.

Having used the EPIS framework retrospectively, we were able to appreciate its value in prospective planning. This permits us to reflect on some lessons: had we used the framework earlier in the CEBHA+ project, we may well have considered what models best fit the IKT intervention in both our inner and outer context, keeping the diversity of our stakeholders as well as challengesanticipated as well as unanticipated-in mind. The current IKT implementation and monitoring has relied on a handful of key individuals within the CEBHA+ team. More training of the rest of the team and perhaps even of stakeholders may have enhanced acceptability, fidelity, adaptation, and fit. Furthermore, as mentioned earlier, more deliberate thought to the sustainment of the value and benefit of the IKT approach would have likely occurred. With respect to capturing our dynamic programme, using a tool such as the framework for reporting adaptations and modifications (FRAME) [74] to capture change would perhaps have been helpful. This could be particularly important in approaching monitoring from a systems lens that needs to adjust for the complex nature of the IKT approach, which naturally introduces limitations to using any framework with inherent constraints and boundaries.

We acknowledge that our reflection has some limitations. Stakeholder engagement often happens on an ad hoc basis by CEBHA+ IKT team members and is not always formally captured. This may have resulted in missing data and limited analysis with room for more elaboration. Furthermore, documenting the process of stakeholder engagement also proved difficult in terms of how best to measure the success of engagement. Finally, research projects within CEBHA+ have started at various time points, resulting in new stakeholders being added to the IKT approach on a regular basis.

Given the reflexive nature of this paper, we recognize that the authors are all researchers on the CEBHA+ project and provide only one perspective of the IKT approach in South Africa. The paper is therefore limited to presentation of our own views and perspectives. However, the importance of stakeholder perspectives has been planned [38] and will be reported in a future publication that seeks to evaluate the CEBHA+ IKT approach across all African partner sites. We envisage that our perspective complements the broader evaluation, as it provides more in-depth contextualized information to help 
interpret the CEBHA+ IKT process and outcome results. Finally, we have not yet been able to reflect on the sustainment phase of the EPIS framework in our analysis given the ongoing implementation of the IKT approach.

\section{Conclusions}

The challenge as well as opportunity in implementation science lies in the very nature of working in complex contexts with changing realities. Adapting the CEBHA+ IKT approach to respond to these changes was what permitted us to be agile, responsive, relevant, and useful to key decision-makers deliberating NCD policies and practices in a time of emergent crises. Bridging IKT with a framework from implementation science can be extremely beneficial not only when reflecting post facto on an IKT approach but also when planning and implementing such strategies. Documenting experiences from South Africa can contribute to strengthening the evidence base of such approaches from an LMIC perspective.

\begin{abstract}
Abbreviations
BMBF: The Federal Ministry of Education and Research, Germany; CDIA: Chronic Disease Initiative for Africa; CEBHA+ : Collaboration for EvidenceBased Healthcare in Africa; CEBHC, SU: Centre for Evidence-Based Health Care, Stellenbosch University; GIZ: Gesellschaft für Internationale Zusammenarbeit, Germany; IKT: Integrated knowledge translation; LMU: Ludwig Maximilian University of Munich; (N)DoH: (National) Department of Health; NCDs: Noncommunicable diseases; SAMRC: South African Medical Research Council.
\end{abstract}

\section{Acknowledgements}

The authors thank Prof. Taryn Young (Stellenbosch University) and Dr Tamara Kredo (South African Medical Research Council) for their support and invaluable contributions to various aspects of the paper. We also acknowledge all the South African CEBHA+ members who are engaging with various stakeholders and take part in quarterly meetings as well as German and African partners involved in implementing and supporting the overall CEBHA+ IKT approach.

\section{Authors' contributions}

NJ spearheaded the development of the manuscript. All authors were involved in the data analysis and interpretation. All authors contributed to the writing of the manuscript, and all authors critically reviewed, read, and approved the final manuscript.

\section{Funding}

This work is part of the Collaboration for Evidence-Based Healthcare and Public Health in Africa (CEBHA+) (http://cebha-plus.org/). This is supported through the Federal Ministry for Education and Research (Germany) of the Research Networks for Health Innovation in Sub-Saharan Africa without restrictions on the research content or approach. The content is solely the responsibility of the authors and does not necessarily represent the official views of the funder.

\section{Availability of data and materials}

The datasets used and/or analysed during the current study are available from the corresponding author on reasonable request.

\section{Declarations}

Ethics approval and consent to participate

Not applicable.
Consent for publication

Not applicable.

\section{Competing interests}

The authors declare that they have no competing interests.

\section{Author details}

${ }^{1}$ Division of Epidemiology and Biostatistics, Centre for Evidence-Based Health Care, Faculty of Medicine and Health Sciences, Stellenbosch University, Cape Town, South Africa. ${ }^{2}$ Department of International Health, Johns Hopkins Bloomberg School of Public Health, Baltimore, USA. ${ }^{3}$ Cochrane South Africa, South African Medical Research Council, Cape Town, South Africa. ${ }^{4}$ School of Public Health, University of the Western Cape, Cape Town, South Africa. ${ }^{5}$ Chronic Disease Initiative for Africa, University of Cape Town, Cape Town, South Africa. ${ }^{6}$ Department of Public Health, Vrije Universiteit Brussel, Brussels, Belgium.

Received: 20 January 2021 Accepted: 3 May 2021

Published online: 17 May 2021

\section{References}

1. Lawrence LM, Bishop A, Curran J. Integrated knowledge translation with public health policy makers: a scoping review. Healthc Policy. 2019;14(3):55-77.

2. Malla C, Aylward P, Ward P. Knowledge translation for public health in low- and middle- income countries: a critical interpretive synthesis. Glob Health Res Policy 2018;3:29-018-0084-9. eCollection 2018.

3. Sanders D, Labonte R, Baum F, Chopra M. Making research matter: a civil society perspective on health research. Bull World Health Organ. 2004;82(10):757-63.

4. Uneke CJ, Aulakh BK, Ezeoha AE, Ndukwe CD, Onwe F. Bridging the divide between research and policy in Nigeria: the role of a health policy advisory committee. J Public Health Policy. 2012;33(4):423.

5. Langlois EV, Montekio VB, Young T, Song K, Alcalde-Rabanal J, Tran N. Enhancing evidence informed policymaking in complex health systems: lessons from multi-site collaborative approaches. Health Res Policy Syst. 2016;14(1):20.

6. Innvær S, Vist G, Trommald M, Oxman A. Health policy-makers' perceptions of their use of evidence: a systematic review. J Health Serv Res Policy. 2002;7(4):239-44.

7. Oliver K, Innvær S, Lorenc T, Woodman J, Thomas J. A systematic review of barriers to and facilitators of the use of evidence by policymakers. BMC Health Serv Res. 2014;14(1):2.

8. Young T, Shearer JC, Naude C, Kredo T, Wiysonge CS, Garner P. Researcher and policymaker dialogue: the Policy BUDDIES Project in Western Cape Province, South Africa. BMJ Glob Health. 2018;3(6):e001130.

9. Orton L, Lloyd-Williams F, Taylor-Robinson D, O'Flaherty M, Capewell S. The use of research evidence in public health decision making processes: systematic review. PLoS ONE. 2011;6(7):e21704.

10. Kothari A, MacLean L, Edwards N. Increasing capacity for knowledge translation: understanding how some researchers engage policy makers. Evid Policy J Res Debate Pract. 2009;8(1):1-21.

11. Jessani NS, Valmeekanathan A, Babcock C, Ling B, Davey-Rothwell MA, Holtgrave DR. Exploring the evolution of engagement between academic public health researchers and decision-makers: from initiation to dissolution. Health Res Policy Syst. 2020. https://doi.org/10.1186/ s12961-019-0516-0.

12. Jessani NS, Siddiqi S, Babcock C, Davey-Rothwell M, Ho S, Holtgrave DR. Factors affecting engagement between academic faculty and decisionmakers: learnings and priorities for a school of public health. Health Res Policy Syst. 2018;16(65):1-15.

13. Wensing M, Grol R. Knowledge translation in health: how implementation science could contribute more. BMC Med. 2019. https://doi.org/10. 1186/s12916-019-1322-9.

14. ECOWAS. Resolution on the use of evidence in developing health care policies, plans, standards and protocols in the ECOWAS region. 2017 (Assembly of Health Ministers). 
15. Ward V, House A, Hamer S. Knowledge brokering: the missing link in the evidence to action chain? Evid Policy J Res Debate Pract. 2009;5(3):267-79.

16. Siegel DS, Waldman DA, Atwater LE, Link AN. Toward a model of the effective transfer of scientific knowledge from academicians to practitioners: qualitative evidence from the commercialization of university technologies. J Eng Technol Manag. 2004;21(1):115-42.

17. Huberman M. Steps toward an integrated model of research utilization. Knowledge. 1987;8(4):586-611.

18. Lomas J. Connecting research and policy. Can J Policy Res. 2000;1(1):140-4.

19. Lavis JN, Robertson D, Woodside JM, McLeod CB, Abelson J. How can research organizations more effectively transfer research knowledge to decision makers? Milbank Q. 2003;81(2):221.

20. Lavis JN, Lomas J, Hamid M, Sewankambo NK. Assessing country-level efforts to link research to action. Bull World Health Organ. 2006;84(8):620.

21. Graham ID, Logan J, Harrison MB, Straus SE, Tetroe J, Caswell W, et al. Lost in knowledge translation: time for a map? J Contin Educ Health Prof. 2006;26(1):13-24

22. Wye L, Cramer H, Carey J, Anthwal R, Rooney J, Robinson R, et al. Knowledge brokers or relationship brokers? The role of an embedded knowledge mobilisation team. Evid Policy J Res Debate Pract. 2018;15(2):277-92.

23. Stanley A, Zussman T. Strengthening networks and building relationships to increase the impact of global development research. 2016. https://doi. org/10.35648/20.500.12413/11781/ii300.

24. $\sin \mathrm{CH}$. The role of intermediaries in getting evidence into policy and practice: some useful lessons from examining consultancy-client relationships. Evid Policy J Res Debate Pract. 2008;4(1):85.

25. Ross S, Lavis J, Rodriguez C, Woodside J, Denis JL. Partnership experiences: involving decision-makers in the research process. J Health Serv Res Policy. 2003;8(Suppl 2):26-34.

26. Jessani NS, Babcock C, Siddiqi S, Davey-Rothwell M, Ho S, Holtgrave DR. Relationships between public health faculty and decision-makers at four governmental levels: a social network analysis. Evid Policy J Res Debate Pract. 2018;14(3):499-522

27. Boyko JA, Lavis JN, Abelson J, Dobbins M, Carter N. Deliberative dialogues as a mechanism for knowledge translation and exchange in health systems decision-making. Soc Sci Med. 2012;75(11):1938-45.

28. Lavis JN, Boyko JA, Gauvin FP. Evaluating deliberative dialogues focussed on healthy public policy. BMC Public Health. 2014;14:1287. https://doi. org/10.1186/1471-2458-14-1287.

29. Wessels M, Lamin D, Manyeh M, King D, Stark L, Lilley S, et al. Chapter 05: How collaboration, early engagement and collective ownership increase research impact: strengthening community-based child protection mechanisms in Sierra Leone. In: Georgalakis J, Jessani N, Oronje R, Ramalingam B, editors., et al., The social realities of knowledge for development. Brighton: IDI/Impact Initiative; 2017. p. 74.

30. Renwick K, Selkrig M, Manathunga C, Keamy RK. Community engagement is... revisiting Boyer's model of scholarship. High Educ Res Dev. 2020;39:1-15.

31. Boyer EL. The scholarship of engagement. Bull Am Acad Arts Sci. 1996:49(7):18-33.

32. Gagliardi AR, Berta W, Kothari A, Boyko J, Urquhart R. Integrated knowledge translation (IKT) in health care: a scoping review. Implement Sci. 2016;11(38):1-12

33. Eccles MP, Mittman BS. Welcome to implementation science. Implement Sci. 2006;1 (1). https://doi.org/10.1186/1748-5908-1-1.

34. Becan JE, Bartkowski JP, Knight DK, et al. A model for rigorously applying the Exploration, Preparation, Implementation, Sustainment (EPIS) framework in the design and measurement of a large scale collaborative multi-site study. Health Justice 2018;6(1):9. https://doi.org/10.1186/ s40352-018-0068-3.

35. Spagnolo J, Gautier L, Champagne F, et al. Reflecting on knowledge translation strategies from global health research projects in Tunisia and the Republic of Cote d'Ivoire. Int J Public Health. 2020;65:1559-1570. https://doi.org/10.1007/s00038-020-01502-3.

36. Kreindler SA. Advancing the evaluation of integrated knowledge translation. Health Res Policy Syst. 2018. https://doi.org/10.1186/ s12961-018-0383-0.
37. Rehfuess EA, Durao S, Kyamanywa P, Meerpohl JJ, Young T, Rohwer A, et al. An approach for setting evidence-based and stakeholder-informed research priorities in low- and middle-income countries. Bull World Health Organ. 2016;94(4):297-305.

38. Pfadenhauer L, Grath T, Delobelle P, Jessani N, Meerpohl JJ, Rohwer A, et al. A mixed method evaluation of the CEBHA+ integrated knowledge translation approach: a protocol. Health Res Policy Syst. 2021. https://doi. org/10.1186/s12961-020-00675-w

39. Jessani NS, Hendricks L, Nicol L, Young T. University curricula in evidenceinformed decision making and knowledge translation: integrating best practice, innovation, and experience for effective teaching and learning. Front Public Health. 2019;7:313.

40. Aarons GA, Hurlburt M, Horwitz SM. Advancing a conceptual model of evidence-based practice implementation in public service sectors. Adm Policy Ment Health. 2011;38(1):4-23.

41. Damschroder LJ, Aron DC, Keith RE, Kirsh SR, Alexander JA, Lowery JC. Fostering implementation of health services research findings into practice: a consolidated framework for advancing implementation science. Implement Sci. 2009;4(1):50

42. Nilsen P. Making sense of implementation theories, models and frameworks. Implement Sci. 2015. https://doi.org/10.1186/s13012-015-0242-0.

43. Jessani NS, Rohwer A, Schmidt BM, Delobelle P, Kredo T. Applying the consolidated framework for implementation research to integrated knowledge translation: experiences from South Africa. Non Communicable Disease Symposium; 2020. Stellenbosch, South Africa.

44. Tabak RG, Khoong EC, Chambers DA, Brownson RC. Bridging research and practice: models for dissemination and implementation research. Am J Prev Med. 2012;43(3):337-50.

45. Rycroft-Malone J, Wilkinson JE, Burton CR, Andrews G, Ariss S, Baker $\mathrm{R}$, et al. Implementing health research through academic and clinical partnerships: a realistic evaluation of the Collaborations for Leadership in Applied Health Research and Care (CLAHRC). Implement Sci. 2011;6(74):1-12.

46. Glasgow RE, Green LW, Taylor MV, Stange KC. An evidence integration triangle for aligning science with policy and practice. Am J Prev Med. 2012:42(6):646-54.

47. Chambers DA, Glasgow RE, Stange KC. The dynamic sustainability framework: addressing the paradox of sustainment amid ongoing change. Implement Sci. 2013;8:117-5908-8-117.

48. Pfadenhauer LM, Gerhardus A, Mozygemba K, Lysdahl KB, Booth A, Hofmann $B$, et al. Making sense of complexity in context and implementation: the context and implementation of complex interventions $(\mathrm{CICl})$ framework. Implement Sci. 2017;12(1):21-017-0552-5.

49. Havelock RG. Planning for innovation through dissemination and utilization of knowledge, Center for Research on Utilization of Scientific Knowledge, Institute for Social Research, University of Michigan. 1979.

50. Lester JP. The utilization of policy analysis by state agency officials. Sci Commun. 1993;14(3):267-90.

51. Lester JP, Wilds LJ. The utilization of public policy analysis: a conceptual framework. Eval Program Plann. 1990;13(3):313-9.

52. Rycroft-Malone J. The PARIHS framework-a framework for guiding the implementation of evidence-based practice. J Nurs Care Qual. 2004:19(4):297-304.

53. Bowen S, Zwi AB. Pathways to "evidence-informed" policy and practice: a framework for action. PLoS Med. 2005;2(7):e166. https://doi.org/10.1371/ journal.pmed.0020166.

54. Aarons GA, Hurlburt M Horwitz SM. Advancing a conceptual model of evidence-based practice implementation in public service sectors. Adm Policy Ment Health Ment Health Serv Res. 2011;38(1):4-23.

55. Neta G, Glasgow RE, Carpenter CR, Grimshaw JM, Rabin BA, Fernandez ME, Brownson RC. A framework for enhancing the value of research for dissemination and implementation. Am J Public Health. 2015;105(1):49-57.

56. Moullin JC, Dickson KS, Stadnick NA, Rabin B, Aarons GA. Systematic review of the exploration, preparation, implementation, sustainment (EPIS) framework. Implement Sci. 2019;14(1):1-018-0842-6.

57. Morse JM, Field PA, editors. Qualitative research methods for health professionals. 2nd ed. SAGE: Thousand Oaks; 1995. https://us.sagepub.com/ en-us/nam/qualitative-research-methods-for-health-professionals/book5 128 
58. Federal Ministry of Education and Research. The Africa Strategy 2014-1028: Africa as Partner in Education and Research. 2014.

59. South African Therapeutic Guidelines Sub-Committee for COVID-19. Covid-19 rapid reviews. 2020; http://www.health.gov.za/index.php/natio nal-essential-medicine-list-committee-nemlc/category/633-covid-19rapid-reviews.

60. Young T, Schoonees A, Lachman A, Kalula S, Mabweazara S, Musa E, et al. Taking stock of the evidence: COVID-19 and diabetes, hypertension, asthma, occupational lung diseases, coronary heart disease, heart failure and stroke. 2020.

61. Pablos-Mendez A, Chunharas S, Lansang MA, Shademani R, Tugwell P. Knowledge translation in global health. Bull World Health Organ. 2005;83(10):723-96862005001000000 (Epub 2005 Nov 10).

62. Haines A, Kuruvilla S, Borchert M. Bridging the implementation gap between knowledge and action for health. Bull World Health Organ. 2004;82(10):724-31; discussion 732.

63. Panisset U, Koehlmoos TP, Alkhatib AH, Pantoja T, Singh P, KengeyKayondo J, et al. Implementation research evidence uptake and use for policy-making. Health Res Policy Syst. 2012;10(1):20.

64. Edwards A, Zweigenthal V, Olivier J. Evidence map of knowledge translation strategies, outcomes, facilitators and barriers in African health systems. Health Res Policy Syst. 2019;17(1):16-019-0419-0.

65. Graham ID, Kothari A, McCutcheon C. Moving knowledge into action for more effective practice, programmes and policy: protocol for a research programme on integrated knowledge translation. Implement Sci. 2018;13(22):1-15.

66. Kasonde JM, Campbell S. Creating a knowledge translation platform: nine lessons from the Zambia forum for health research. Health Res Policy Syst. 2012. https://doi.org/10.1186/1478-4505-10-31.

67. Berman J, Mitambo C, Matanje-Mwagomba B, Khan S, Kachimanga C, Wroe E, et al. Building a knowledge translation platform in Malaw to support evidence-informed health policy. Health Res Policy Syst. 2015:13(73):1-5.
68. Jessani N, Boulay M, Bennett S. Do academic knowledge brokers exist? Using social network analysis to explore academic research-to-policy networks from six schools of public health in Kenya. Health Policy Plan. 2016;31(5):600-11.

69. Hanson D, Hanson J, Vardon P, McFarlane K, Speare R, Dürrheim D. Documenting the development of social capital in a community Safety Promotion Network: it's not what you know but who you know. Health Promot J Austr. 2008;19(2):144-51.

70. Long JC, Cunningham FC, Wiley J, Carswell P, Braithwaite J. Leadership in complex networks: the importance of network position and strategic action in a translational cancer research network. Implement Sci. 2013;8(1):122.

71. Bornbaum CC, Kornas K, Peirson L, Rosella LC. Exploring the function and effectiveness of knowledge brokers as facilitators of knowledge translation in health-related settings: a systematic review and thematic analysis. Implement Sci. 2015;10(1):162.

72. Cvitanovic C, Cunningham R, Dowd AM, Howden SM, Putten El. Using social network analysis to monitor and assess the effectiveness of knowledge brokers at connecting scientists and decision-makers: an Australian case study. Environ Policy Gov. 2017;27(3):256-69.

73. Boaz A, Hanney S, Borst R, O'Shea A, Kok M. How to engage stakeholders in research: design principles to support improvement. Health Res Policy Syst. 2018;16(60):1-9.

74. Wiltsey Stirman S, Baumann AA, Miller CJ. The FRAME: an expanded framework for reporting adaptations and modifications to evidencebased interventions. Implement Sci. 2019. https://doi.org/10.1186/ s13012-019-0898-y.

\section{Publisher's Note}

Springer Nature remains neutral with regard to jurisdictional claims in published maps and institutional affiliations.
Ready to submit your research? Choose BMC and benefit from:

- fast, convenient online submission

- thorough peer review by experienced researchers in your field

- rapid publication on acceptance

- support for research data, including large and complex data types

- gold Open Access which fosters wider collaboration and increased citations

- maximum visibility for your research: over $100 \mathrm{M}$ website views per year

At BMC, research is always in progress.

Learn more biomedcentral.com/submissions 